\title{
Fadéla M’Rabet, Une enfance singulière
}

\section{Ilaria Vitali}

\section{(2) OpenEdition}

\section{Journals}

\section{Edizione digitale}

URL: http://journals.openedition.org/studifrancesi/36796

DOI: 10.4000/studifrancesi.36796

ISSN: 2427-5856

\section{Editore}

Rosenberg \& Sellier

\section{Edizione cartacea}

Data di pubblicazione: 1 juillet 2005

Paginazione: 207

ISSN: 0039-2944

\section{Notizia bibliografica digitale}

Ilaria Vitali, «Fadéla M'Rabet, Une enfance singulière», Studi Francesi [Online], 145 (XLIX | I) | 2005, online dal 30 novembre 2015, consultato il 18 avril 2021. URL: http://journals.openedition.org/studifrancesi/ 36796 ; DOI: https://doi.org/10.4000/studifrancesi.36796

\section{Questo documento è stato generato automaticamente il 18 avril 2021.}

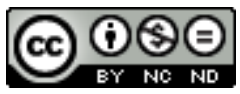

Studi Francesi è distribuita con Licenza Creative Commons Attribuzione - Non commerciale - Non opere derivate 4.0 Internazionale. 


\title{
Fadéla M'Rabet, Une enfance singulière
}

\author{
Ilaria Vitali
}

\section{NOTIZIA}

FADÉLA M'RABET, Une enfance singulière, Paris, Balland, 2003, pp. 118.

1 Racconto polifonico e coinvolgente, Une enfance singulière, narra l'esuberante genealogia di una famiglia maghrebina attraverso gli occhi delle donne. A partire dalla nonna materna, Djedda, « déesse tutélaire de la tribu », la storia della famiglia dipana il suo filo attraverso il tempo, seguendo la linea della matrilinearità. Si è tentati di inserire il romanzo nel décor delle grandi epopee famigliari francofone, come Texaco di Chamoiseau, o latinoamericane, come Cien años de soledad di Marquez. Ma qui, la particolarità del romanzo è la messa in risalto di un universo interamente femminile, ricco quanto misterioso. Cominciando da Fella, cugina siamese con cui la protagonista compie le prime esperienze all'interno di uno spazio famigliare chiuso, fino a Yasmina, morta a soli 14 anni, sono tanti i volti di donna a cui Fadéla M'Rabet ridona voce, conferendo dignità perdute. Oltre ad essere stata una delle prime femministe della storia maghrebina, l'autrice si mostra qui interessata alla dinamica collettiva e sociale, senza dimenticare la singolarità del percorso individuale della donna, troppo spesso sopraffatta dallo scorrere collettivo di vite identiche, intercambiabili e riproducibili all'infinito, come prestampati in una tela pop-art. «C'était comme chez Andy Warhol, les mêmes images qui se répétaient à l'infini dans l'espace et dans le temps. Des images de Mater Dolorosa. ».

Una rievocazione del passato, farcita di commenti e riflessioni, che non si limitano tuttavia alla sterile riproduzione di un cliché, ma vogliono indagare a fondo la realtà femminile magrebina, universo sepolto e tuttavia fecondo, creativo. Pur affrontando il tema del colonialismo francese e dei problemi d'integrazione che ne costituiscono la toile de fond, il romanzo di Fadéla M'Rabet vuole raccontare soprattutto momenti di 
gioia e paradossale libertà in un mondo dominato da figure maschili. Il quadro che ne emerge è un ritratto intimo, affettivo, vitale, a tratti gioioso. Narrando le vite di donne solo apparentemente senza voce, l'autrice sembra giocare sull'omofonia del termine francese voix/voie: la "voce" come "via". Via di fuga. Via di scampo. Come vita. Speranza. È infatti attraverso questa "voce", che l'autrice crea una "via" possibile, disegnando un cammino nuovo e originale all'interno di uno spazio silente. 